\title{
A Comparative Evaluation of Mean Completeness in Different Impression Techniques for Post Space: An In Vitro Study
}

\author{
Urvashi Kukreja ${ }^{5}$ \\ ${ }^{1}$ Department of Dentistry, Civil Hospital, Hisar, Haryana, India \\ ${ }^{2}$ Department of Orthodontics, JCD Dental College, Sirsa, Haryana, \\ India \\ ${ }^{3}$ Department of Conservative and Endodontics, College of Dental \\ Sciences, Mullana, Ambala, Haryana, India \\ ${ }^{4}$ Department of Periodontics, Himachal Institute of Dental Sciences, \\ Poanta Shaib, Himachal Pradesh, India \\ ${ }^{5}$ Department of Prosthodontics, College of Dental Sciences, \\ Mullana, Ambala, Haryana, India
}

Vikram Panghal ${ }^{1}$ Sangeeta Sunda ${ }^{2} \quad$ Abhishek Bansal $^{3} \quad$ Navneet Kukreja $^{3} \quad$ Jyoti Bansal $^{4}$

\author{
Address for correspondence Vikram Panghal, MDS, Department \\ of Dentistry, Civil Hospital, Hisar 125001, Haryana, India \\ (e-mail: vikrampanghal1981@gmail.com).
}

\begin{abstract}
Keywords

- endodontically treated teeth

- impression techniques

- post

- root canal

- restoration

Endodontic therapy enables several advantages including maintenance of a natural tooth with restoration of its esthetics and functions. But endodontically treated teeth are often mutilated by caries fracture or previous restoration. Historically, many methods have been attempted in the search for an ideal foundation or build-up design for endodontically treated teeth. Dr. G. V. Black developed a porcelain-faced crown secured in place with a screw embedded in gold filling. Richmond crown was designed as a self-contained restoration with the post being a part of the final crown. Post can be either prefabricated or custom made. Custom-made post can be fabricated by either direct or indirect technique. In the indirect technique, impression taken should exactly replicate the parameters such as design, length, surface configuration, and diameter. The main problems while taking the impression of post space are incorporation of voids in the radicular portion and the inability to produce accurate impression in all dimensions. It mainly affects the quality of fabricated cast post. Therefore, this study is undertaken to compare the different impression techniques used for post space. It is expected that the study will reveal some useful information about the impression techniques that can be used to reproduce accurate and void-free impression of post space.
\end{abstract}

\section{Introduction}

With the increasing number of teeth being retained by endodontic therapy, there is a concomitant need to have the knowledge and skill to restore these teeth. In modern times, the post-and-core systems are widely used as a means of restoring badly damaged teeth. ${ }^{1}$ When there is an extensive loss of tooth substance, the restoration of endodontically treated tooth requires intracanal post that fits into a space created by the removal of the root filling material. Over the years, many designs and techniques of post-and-core system have evolved to restore severely mutilated teeth. Custom cast post and core is the method of choice to restore such teeth..$^{2-6}$ In the direct technique, a prefabricated plastic post is placed directly into the prepared post space, and the impression of the post space is obtained with autopolymerizing resin. In an indirect technique, an impression of the prepared post space is
DOI https://doi.org/

10.1055/s-0038-1673496. ISSN 2321-1482.
(C2018 Bhojia Dental College and Hospital affiliated to Himachal Pradesh University
License terms

(요 (1) $\odot \circledast$ 
made, which is used to fabricate the post-core pattern. This is thus casted using conventional techniques. In an indirect technique, the impression of the post space is critical for the success of post-and-core systems. The main problems encountered while making the impression of post space is incorporation of voids in the radicular portion and the inability to produce accurate impression in all dimensions. The faulty impression then results in inaccurate cast posts. The existing dental literature is replete with information regarding various impression methods for the prepared post space. However, there is little information regarding the best method for impression of the post space with the currently available impression materials. Therefore, this study is undertaken to compare the different impression techniques used for post space and their subsequent analyses.

\section{Aims and Objectives}

The purpose of this study was to compare mean completeness of different impression techniques for the post space in endodontically treated anterior teeth.

\section{Materials and Methods}

This in vitro study was performed in the Department of Prosthodontics, Sardar Patel Post Graduate Institute of Dental and Medical Sciences, Lucknow, India.

The following standardized materials were used for the purpose of study:

- Material and equipment for the preparation of the post space:

- Freshly extracted sound maxillary central incisors.

- Glutaraldehyde and xylene solution for sterilizing the teeth.

- Gutta-percha for obturating the prepared canal.

- Micromotor with a contra-angle handpiece (speed control: 5,000-35,000 rpm) to prepare the post space.

- Preparation kit for preparing the extracted central incisors includes the following:

1. Endodontic files for instrumentation of root canals.

2. Spreader or plungers for the obturation of the canals.

3. Peeso reamers for removing gutta-percha.

4. Gates Glidden drill for removing gutta-percha.

- Materials and equipment for custom tray fabrication:

- Self-polymerizing acrylic resin (Dentsply) to make custom tray.

- Dappen dish for mixing the resin.

- Petroleum jelly and cotton for lubricating the prepared canal.

- Materials for the impression of post space:

- Polyvinyl siloxane (addition) impression material (3M ESPE).

- 26-gauze orthodontic wire.

- Disposable syringe $(0.25 \mathrm{~mm})$.

- Irrigating syringe.

- Lentulo spiral.

- Irrigating syringe.
- Equipment for the analysis of impression:

- Schott-Renfert Stereo Microscope.

- Illumination magnifying glass.

\section{Method}

To standardize the procedure, standard instruments and equipment were used to make post space. The extracted maxillary central incisors were disinfected for 48 hours in glutaraldehyde solution and stored in normal saline solution. Central incisors were prepared for complete porcelain-fused-to-metal (PFM) crown. The facial and proximal reduction of $1.5 \mathrm{~mm}$ with a shoulder finish line and $0.5 \mathrm{~mm}$ with a chamfer finish line lingually was given. An incisal reduction of $2 \mathrm{~mm}$ was performed. A further incisal reduction of $4 \mathrm{~mm}$ was performed on a flat plane for a core restoration. Access to root canal was made. Pulp was extirpated and biomechanical preparation was performed up to K-file no. 80 using Schilder method. Obturation was performed with gutta-percha using the lateral condensation technique. Post space was prepared in the root canal with a no. 3 Peeso reamer, leaving $4 \mathrm{~mm}$ of gutta-percha at the apex, and enlarged with a no. 5 Peeso reamer. Five such teeth were prepared. Custom trays were made to carry heavy-body impression material to make an impression of the prepared teeth. Five different techniques using light-body additional polyvinyl silicone impression material were used to obtain the impression of post space $(-$ Fig. 1$)$. The impression, made for the post space, was evaluated for completeness.

\section{Result}

This study was conducted in Birbal Sahni Institute of Palaeobotany, Lucknow, to compare the different impression techniques for the surface characteristics. Surface characteristics were measured in terms of completeness. Observations were made under scanning electron microscope ( - Fig. 2). A total of 125 samples using five different impression techniques, that is, 25 samples in each technique, were evaluated.

Comparison of mean completeness in different impression techniques was performed (-Table 1 ). It was observed that mean completeness was maximum using

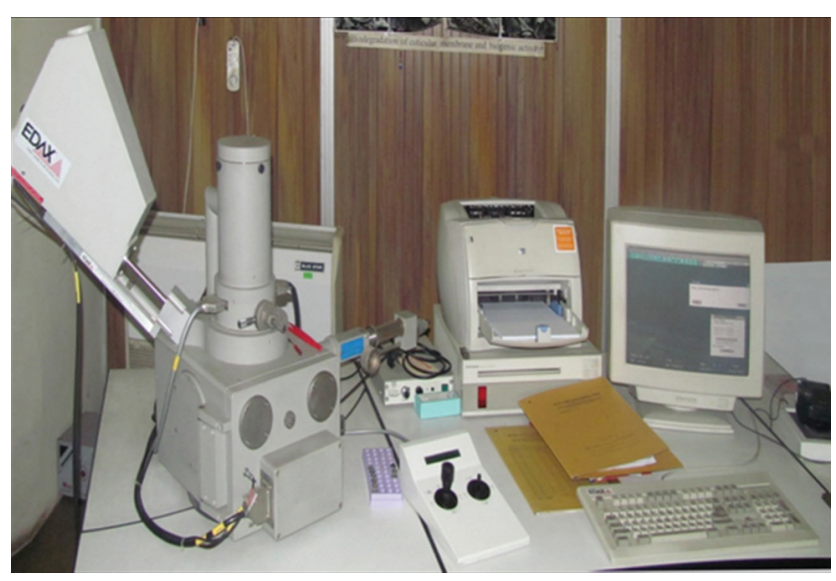

Fig. 1 Five different techniques for obtaining impression of post space. 


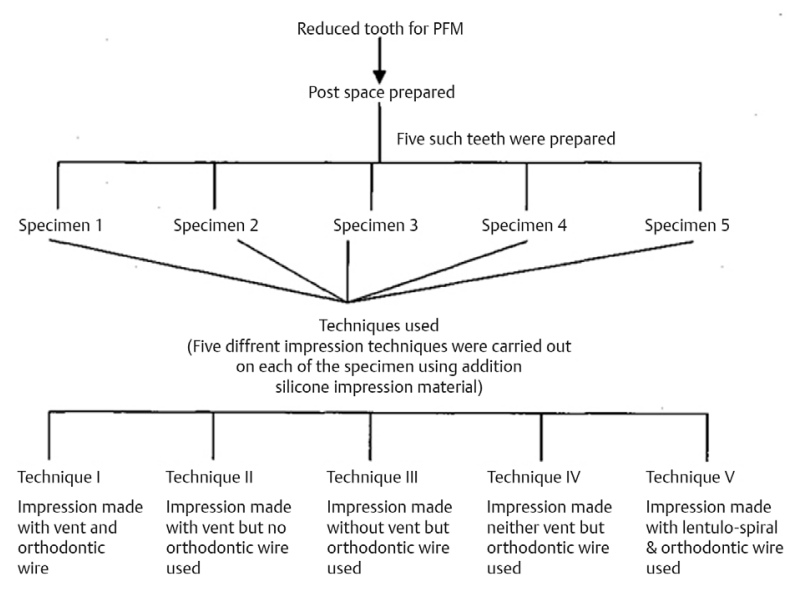

Fig. 2 Scanning electron microscope for comparing mean completeness in different impression techniques. PFM, porcelain-fused-to-metal.

Table 1 Comparison of mean completeness in different techniques

\begin{tabular}{|l|l|l|l|l|l|l|}
\hline S. no. & Technique & $\begin{array}{c}\text { No. of } \\
\text { cases }\end{array}$ & Mean & SD & Min & Max \\
\hline 1. & I & 25 & 5.99 & 0.04 & 5.8 & 6 \\
\hline 2. & II & 25 & 5.26 & 0.54 & 4.5 & 6 \\
\hline 3. & III & 25 & 4.96 & 0.53 & 4 & 5.5 \\
\hline 4. & IV & 25 & 4.50 & 0.46 & 4 & 5 \\
\hline 5. & V & 25 & 5.40 & 0.50 & 5 & 6 \\
\hline
\end{tabular}

Abbreviation: SD, standard deviation.

Note: Values are given as mean \pm SD.

technique I (5.99 \pm 0.04$)$ and minimum using technique IV $(4.50 \pm 0.46)$. The minimum completeness value for a sample was observed to be 4 units in at least one sample using technique III and technique IV, whereas the maximum completeness value was observed to be 6 units in at least three techniques (techniques I, II, and V).

On the basis of the aforementioned observations, the following order of mean completeness was observed for different techniques:

Technique I $>$ Technique $\mathrm{II} \simeq$ Technique $\mathrm{V}>$ Technique III $>$ Technique IV

\section{Discussion}

Endodontically treated teeth generally require post-and-core system to develop a tooth preparation necessary to provide retention and adequate resistance form for the success of the definitive crown. There are two methods by which impression of post space core can be made: direct and indirect techniques. Out of these, the indirect method is preferred as it takes lesser chair-side time, especially for multiple restoration. ${ }^{7.8}$ In the indirect technique, an impression of the prepared post space is made to form a working cast upon which the post-core pattern is then fabricated. Regardless of the technique employed, the impression for the post must record accurately the surface details along the entire length of the post space. While the impression is being made, due to insufficient escapement for air, voids commonly get incorporated in the radicular portion of the post impression, leading to inaccurate fit of the cast post. ${ }^{9}$ This study was conducted to compare different post space impression techniques using polyvinyl siloxane impression material to determine which technique produced the most accurate impression of the post space. Polyvinyl siloxane impression material was chosen to make the impression of the post space as it produces dimensionally stable impressions, ${ }^{10,11}$ with surface detail recorded as minutely as $0.02 \mathrm{~mm} .{ }^{12}$ Also, they exhibit the best recovery from deformation during removal from the mouth and best wettability. ${ }^{12}$ Light-body polyvinyl siloxane impression material was used for the impression of post space, and heavy-body polyvinyl siloxane impression material was used as tray material. For this study, freshly extracted sound maxillary central incisors were selected as the root canal morphology-of-maxillary central incisor is comparatively straighter than the other teeth. The maxillary central incisors were stored in glutaraldehyde solution for 48 hours to provide a practical level of infection control and safety. ${ }^{13}$ The maxillary central incisor teeth were prepared to receive full veneer PFM crowns. PFM crown combines the strength, durability, and marginal fit of cast metal with the esthetics of an all-ceramic crown. ${ }^{14-16}$ The Schilder method of canal preparation was used to form continuously tapering funnel with the narrowest diameter at the apex and the widest diameter at the cervical portion of the canal. The canal was prepared with up to no. 80 K-file. The narrow apical opening acted like a matrix against which gutta-percha was condensed. This apical constriction prevented the excess filling material from being forced beyond the apical foramen. ${ }^{2}$ The post space was prepared using Peeso reamers up to no. 5, with up to $8 \mathrm{~mm}$ in length, leaving $4 \mathrm{~mm}$ of gutta-percha at the apex. The prepared post space was $1.5 \mathrm{~mm}$ in diameter as proposed by Shillingburg. Custom trays with $2-\mathrm{mm}$ wax relief were made to carry heavy-body impression material to make the impression. ${ }^{17}$ The post space prepared was lubricated with petroleum jelly to facilitate the removal of the impression without distortion. Following techniques were used to make the impression of post space with lightbody polyvinyl siloxane impression material. In technique I, a 24-gauge anesthetic needle was used to act as an escape way for the air. After the impression material was injected into the post space, the anesthetic needle was removed and a 26-gauge orthodontic wire bent in J shape was inserted for the reinforcement of the light-body impression material in the post space ${ }^{18,19}$ and to replace the space created due to the removal of the anesthetic needle. In technique II, the 24-gauge anesthetic needle was used to act as a vent, but no orthodontic wire was used for reinforcement. In technique III, the anesthetic needle was not used, but the orthodontic wire was used for reinforcement. In technique IV, neither the anesthetic needle nor the orthodontic wire was used. The impression material was introduced by the syringe only. In technique $\mathrm{V}$, lentulo spiral was used to 
insert impression material in the post space in increments by using a slow-speed handpiece and then the orthodontic wire was used for reinforcement. All the impressions thus obtained were evaluated under stereo-electron microscope. Observations were made for completeness of impression. Completeness of the impression along the post space length was maximum in technique I, as air was allowed to escape through a vent and thus the impression material was able to occupy whole of the prepared post space. The completeness of the impression was observed to be in the following order:

Technique $\mathrm{I}>$ Technique $\mathrm{II}=$ Technique $\mathrm{V}>$ Technique III $>$ Technique IV.

The impression was incomplete in technique IV. These results are in confirmation with the previous study performed by Chee et al. ${ }^{13}$ Another study by Baraban ${ }^{7}$ described three methods for taking impression for post and core and concluded that care should be taken not to trap air while making the impression with rubber base impression material. Finally, it can be derived from this study that attention should be given to the technique that produced no voids and an accurate impression of post space.

\section{Conclusion}

Based on the observation made, statistically analyzed and duly discussed following conclusions were drawn. In technique I, impression made using a 24-gauge anesthetic needle which acted as a vent at the apex when injecting light-body polyvinyl siloxane impression material followed by removal of the needle and placement of the orthodontic wire to the depth of preparation resulted in a maximum number of void-free impressions.

- In technique $\mathrm{V}$, in contrast, when a lentulo spiral and orthodontic wire was used, the number of voids was maximum.

- In technique I, completeness of impression was maximum, whereas in technique IV, the completeness of impression was minimum.

- Completeness of impression with various techniques showed a statistically significant difference.

\section{Conflict of Interest}

None.

\section{References}

1 Bergman B, Lundquist P, Sjögren U, Sundquist G. Restorative and endodontic results after treatment with cast posts and cores. J Prosthet Dent 1989;61(1):10-15

2 Cohen S, Burns R. Pathways of the Pulp. 4th ed. St. Louis, MO: CV Mosby; 1987:640-684

3 Goerig AC, Mueninghoff LA. Management of the endodontically treated tooth. Part II: technique. J Prosthet Dent 1983;49(4):491-497

4 Morgano SM, Milot P. Clinical success of cast metal posts and cores. J Prosthet Dent 1993;70(1):11-16

5 Silverstein $\mathrm{WH}$. The reinforcement of weakened pulpless teeth. J Prosthet Dent 1964;14:372-381

6 Weine FS. Endodontic Therapy. 5th ed. St. Louis, MO: CV Mosby; 1996:776-779

7 Baraban DJ. The restoration of endodontically treated teeth: an update. J Prosthet Dent 1988;59(5):553-558

8 Rosen H. Operative procedures on mutilated endodontically treated teeth. J Prosthet Dent 1961;11:973-986

9 Rud J, Omnell KA. Root fractures due to corrosion. Diagnostic aspects. Scand J Dent Res 1970;78(5):397-403

10 Marcinak CF, Young FA, Draughn RA, Flemming WR. Linear dimensional changes in elastic impression materials. J Dent Res 1980;59(7):1152-1155

11 Newell M, Myers GE. Silicone impression material. J Prosthet Dent 1961;12(2):951-961

12 Craig RG, Ward ML. Restorative Dental Materials. 10th ed. St. Louis, MO: CV Mosby; 1996:302-313

13 Chee WWL, Cho GC, Marzola R. An in vitro comparison of 5 techniques for impressing dowel space preparations. J Prosthodont 2000;9(1):19-22

14 Barkhordar RA, Radke R, Abbasi J. Effect of metal collars on resistance of endodontically treated teeth to root fracture. J Prosthet Dent 1989;61(6):676-678

15 Cho GC, Donovan IE, Chec WWL. Tensile bond strength of polyvinyl siloxane impression bonded to a custom tray as a function of drying time: part I. J Prosthet Dent 1955;73:415-423

16 Shillingburg HT, Kessler JC. Restoration of Endodontically Treated Tooth. Chicago, IL: Quintessence Publishing; 1982; 13:203

17 Barnes BW, Sieweke JC, Wallance WS, Rogers BL. Elastomeric impression material: effect of bulk on accuracy. J Prosthet Dent 1979;41(3):304-307

18 Johnston JF, Philips RW, Dykema RW. Modern Practice in Crown and Bridge Prosthodontics. 3rd ed. Philadelphia, PA: WB Saunders; 1971:608

19 Kantor ME, Pines MS. A comparative study of restorative techniques for pulpless teeth. J Prosthet Dent 1977;38(4):405-412 